\title{
Safety and efficacy of atezolizumab in the treatment of cancers: a systematic review and pooled-analysis
}

This article was published in the following Dove Medical Press journal: Drug Design, Development and Therapy

\author{
Yan Tie ${ }^{1,2}$ \\ Hui Yang' \\ Rui Zhao ${ }^{3}$ \\ Heng Zheng ${ }^{4}$ \\ Daoke Yang ${ }^{5}$ \\ Jingyi Zhao ${ }^{5}$ \\ Ming Liu ${ }^{1,2}$ \\ 'Cancer Center, West China Hospital, \\ Sichuan University, Chengdu, China; \\ ${ }^{2}$ State Key Laboratory of Biotherapy \\ and Collaborative Innovation Center \\ of Biotherapy, West China Hospital, \\ Sichuan University, Chengdu, China; \\ ${ }^{3}$ Department of Gastrointestinal \\ Surgery, West China Hospital, \\ Sichuan University, Chengdu, \\ China; ${ }^{4}$ Department of Gynecology, \\ West China Second Hospital, \\ Sichuan University, Chengdu, China; \\ ${ }^{5}$ Department of Medical Oncology, \\ First Affiliated Hospital of Zhengzhou \\ University, Zhengzhou University, \\ Zhengzhou, China
}

Correspondence: Ming Liu

Cancer Center, West China Hospital,

Sichuan University, 37 Guoxue Alley,

Chengdu 61004I, China

Tel +862885475576

Fax +862885475576

Email mingliu721@aliyun.com
Purpose: Immune checkpoint inhibitors have developed rapidly and have demonstrated antitumor activity in various cancers. To evaluate the safety and efficacy of atezolizumab in treating cancers, we conducted this meta-analysis.

Methods: Embase, PubMed, MEDLINE, the Central Register of Controlled Trials of the Cochrane Library, and the American Society of Clinical Oncology database were searched for relevant studies. The primary outcomes were any grade adverse events (AEs) and grade $\geq 3$ AEs. The secondary outcomes were overall objective response rate, pooled 6-month progression-free survival (PFS) rate, 1-year overall survival (OS) rate, median PFS, and median OS.

Results: Our meta-analysis was based on 14 clinical trials with 3,266 patients. The total risk of any grade AEs reached $69 \%$, while grade $\geq 3$ AEs happened in only $13 \%$ of participants. The overall atezolizumab-related death rate was $0.17 \%$. Major common AEs involved fatigue (24.5\%), decreased appetite (13.2\%), nausea (12.3\%), diarrhea (10.8\%), pyrexia $(10.7 \%)$, pruritus (9.6\%), cough $(9.5 \%)$, edema peripheral (8.6\%), and rash (8.4\%). The most common severe AEs were fatigue $(2.2 \%)$, anemia $(1.9 \%)$, and dyspnea (1.9\%). Meanwhile, we found that $6 \%$ patients reached complete response and $16 \%$ partial response. The pooled 6-month PFS rate and 1-year OS rate were 0.36 ( $95 \%$ CI: $0.31-0.41)$ and 0.55 (95\% CI: $0.49-0.61)$, respectively. The median PFS varied from 1.5 to 6.1 months, and the median OS ranged from 5.9 to 28.9 months.

Conclusion: Atezolizumab has a considerable potential in treating cancers with an acceptable risk profile.

Keywords: atezolizumab, safety, efficacy, cancer, meta-analysis

\section{Introduction}

Cancer is a leading cause of death in economically developing and developed countries and has become a major public health problem worldwide. ${ }^{1}$ With traditional therapies like surgery, chemotherapy, and radiotherapy, there is still a large proportion of tumor progression because of its invasive and metastatic characteristics. ${ }^{2}$ Therefore, immunotherapy is effective in various cancers and has become a growing part of cancer treatment. ${ }^{3}$

The interaction of antigens expressed on tumor cells and receptors on $\mathrm{T}$ cells would produce inhibitory signals to $\mathrm{T}$ cells. ${ }^{4}$ After that, T-cell-mediated immunity is suppressed and tumor cells would escape from immune surveillance and lead to disease progression. ${ }^{4}$ These molecular pathways of interaction are called immune checkpoints as "the brake" of immune system..$^{5}$ Immunotherapy is based on using immune checkpoint inhibitors to blockade the interaction of immune checkpoints and enable the immune response against tumor cells. ${ }^{3}$ The rapid development of checkpoint inhibitors is changing the landscape of cancer treatments. 
Programmed death 1/programmed death ligand 1 (PD-1/ PD-L1) pathway is an important part of immunotherapy and works in the effector phase of immune cell cycle. ${ }^{3}$ PD-1 is highly expressed on activated T lymphocytes and other tumor-infiltrating immune cells, which can specifically combine with PD-L1 and programmed death ligand 2 (PD-L2) and lead to negative regulation of T-cell function., Expression of PD-L1 in the tumor microenvironment prompts immune escape because of the significant role of T lymphocytes played in acquired antitumor immunity. ${ }^{6,7}$ PD-L1 is broadly expressed on various cancers, including lung cancer (LC), urothelial carcinoma (UC), colorectal cancer, ovarian cancer (OC), melanoma, and glioblastoma. ${ }^{8}$ Blockade of the PD-1/PD-L1 pathway has been shown to produce overall survival (OS) benefits in melanoma, nonsmall-cell lung cancer (NSCLC), and renal cell carcinoma (RCC). ${ }^{9-11}$ Anti-PD-1 antibodies have demonstrated to result in tolerable adverse events (AEs) and drug-related deaths in cancer treatment. ${ }^{12}$

Atezolizumab is a high-affinity human IgG1 monoclonal antibody that binds selectively to PD-L1 and prevents the binding of PD-L1 to PD-1 and B7-1, which enhances the magnitude and quality of the tumor-specific T-cell responses, resulting in improved antitumor activity. ${ }^{13,14}$ In this way, T-cell activation is enabled and tumor cell death is ultimately induced. ${ }^{15}$

So far, a series of clinical trials on atezolizumab for solid cancers, like UC, LC, and OC, have been completed. However, there is still no evidence-based systematic review on the safety and efficacy of atezolizumab in various solid tumors. This meta-analysis focused on the safety and efficacy of atezolizumab in various advanced or metastatic malignancies and offered evidence-based references for clinicians.

\section{Methods}

\section{Literature search}

Studies were searched in the following databases: Embase, PubMed, MEDLINE, and the Central Register of Controlled Trials of the Cochrane Library without any language restrictions (up to June 9, 2018). The following were used as the specific search strategy: "atezolizumab" or "MPDL3280A." Moreover, the American Society of Clinical Oncology database was searched for relevant studies to find additional publications. After duplicates eliminated, full texts were downloaded and assessed by two reviewers for eligibility independently. A third author adjudicated the possible disagreements.

\section{Inclusion and exclusion criteria}

Included articles in our work had to satisfy the following criteria: 1) the study must be a clinical trial concerning the safety or efficacy of atezolizumab in cancer treatment; 2) the study must report any of the following information: drug-related AEs, objective response rate (ORR), 6-month progression-free survival (PFS) rate, and 1-year OS rate.

The exclusion criteria were as follows: 1) studies were not clinical trials or not related to our research topics; 2) studies lacked necessary data; 3) studies involved less than ten patients; 4) retrospective studies, expert opinions, editorials, or letters.

\section{Data extraction}

This meta-analysis extracted data including first author, published year, publication name, ClinicalTrials.gov number, study phase, study design, cancer types, intervention methods, number of patients, patients' age, ORR, complete response rate (CRR), partial response rate (PRR), stable disease rate, 1-year OS rate, 6-month PFS rate, follow-up time, any grade AEs, grade $\geq 3$ AEs, and drug-related deaths. Six-month PFS rate, 1 -year OS rate, any grade AEs, and grade $\geq 3$ AEs were collected directly. ORR was collected directly or calculated according to CRR and PRR. Two reviewers performed data extraction independently, and disagreements were resolved by a third reviewer.

\section{Statistical analyses}

The statistical analyses involved in this work were performed by Review Manager 5.2, STATA 12.0, and Comprehensive Meta-Analysis V2. The efficacy of atezolizumab in tumors was evaluated by calculating overall ORR, pooled 6-month PFS rate, and 1-year OS rate along with 95\% CI. The safety was evaluated by calculating the overall risk of any grade AEs and grade $\geq 3$ AEs and exhibition of common drug-related AEs. Objective responses were judged according to Response Evaluation Criteria in Solid Tumors (RECIST) version 1.1 or immune-modified RECIST criteria. ${ }^{16,17} \mathrm{ORR}=[$ (complete responses + partial responses) / total no. of patients] $\times 100$. The OR was used to compare atezolizumab with chemotherapeutics and PD-L1-positive expression patients with PD-L1-negative expression patients, respectively. $P<0.05$ or $95 \% \mathrm{CI}$ of OR, not covering 1, suggested that a statistical significance existed between the experimental group and control group. ${ }^{18}$ Inconsistency index $\left(I^{2}\right)$ and chi-squared test were used to detect the heterogeneity among studies. $P$-value $<0.05$ and $I^{2}$ value $>50 \%$ suggested the existence of heterogeneity. ${ }^{18}$ When statistical heterogeneity 
was identified, we could choose random, otherwise we selected fixed effects model..$^{18}$ Then we performed subgroup analysis by study phase, study design, and cancer type to identify the source of heterogeneity accordingly. Begg's and Egger's funnel plot asymmetry tests were used to investigate publication bias. ${ }^{19}$

\section{Quality evaluation}

Methodological quality of the included articles was assessed by two experienced reviewers to ensure consistency using the Cochrane Collaboration's risk of bias tool Review Manager 5.2. Quality assessments included random sequence generation, allocation concealment, blinding of participants and personnel, blinding of outcome reporting, incomplete outcome data, selective reporting, and other items. Studies were graded as low, unclear, or high risk of bias. Discrepancies were resolved by discussion.

\section{Results}

\section{Study selection}

The search strategy produced 674 hits through computerized electronic databases searching. Five hundred sixteen studies were screened after removing the duplicates. Then 479 studies were excluded by screening the title and abstract of each record according to the inclusion and exclusion criteria. After removing retrospective articles and those utilizing combination therapy and lacking necessary data, eleven studies were included. Furthermore, 43 abstracts were identified from the American Society of Clinical Oncology database. Then three eligible abstracts were incorporated in our work. Finally, 14 studies were included in this metaanalysis..$^{14,20-32}$ The procedure of study selection is shown in Figure 1.

\section{Study characteristics}

The included studies in this work were published from 2014 to 2017. The characteristics of included studies are shown in Table 1. We assessed 3,266 patients in total. Two thousand four hundred ninety-six patients received atezolizumab, 568 patients received chemotherapeutics like docetaxel, and 101 patients received sunitinib. All these studies were prospective clinical trials, most of which had ClinicalTrials.gov numbers. Among these studies, there were seven phase I articles, six phase II studies, and one phase III

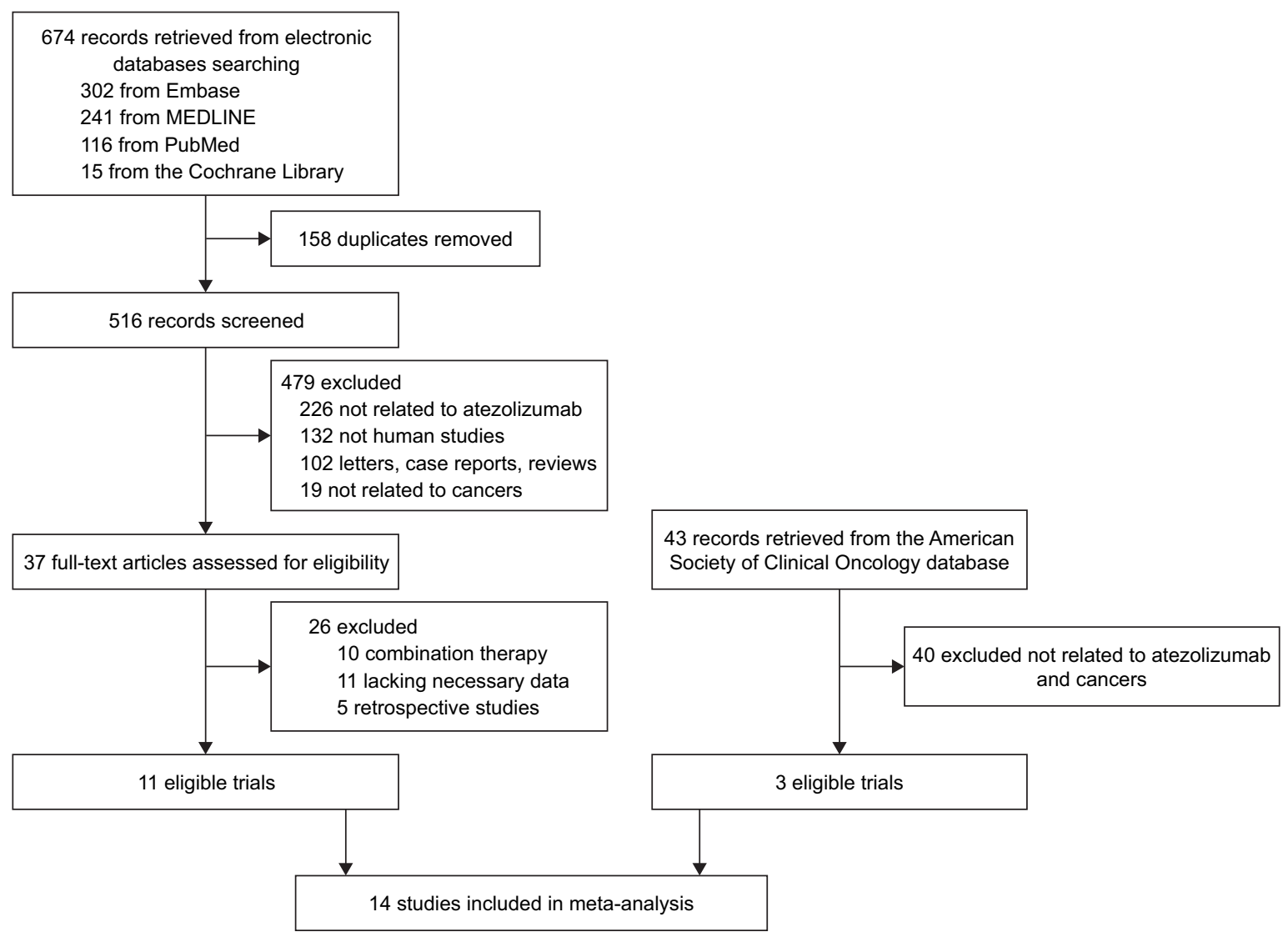

Figure I The procedures and results of study selection.

Note: A total of 14 studies were selected to determine the efficacy and safety of atezolizumab in treating cancers. 


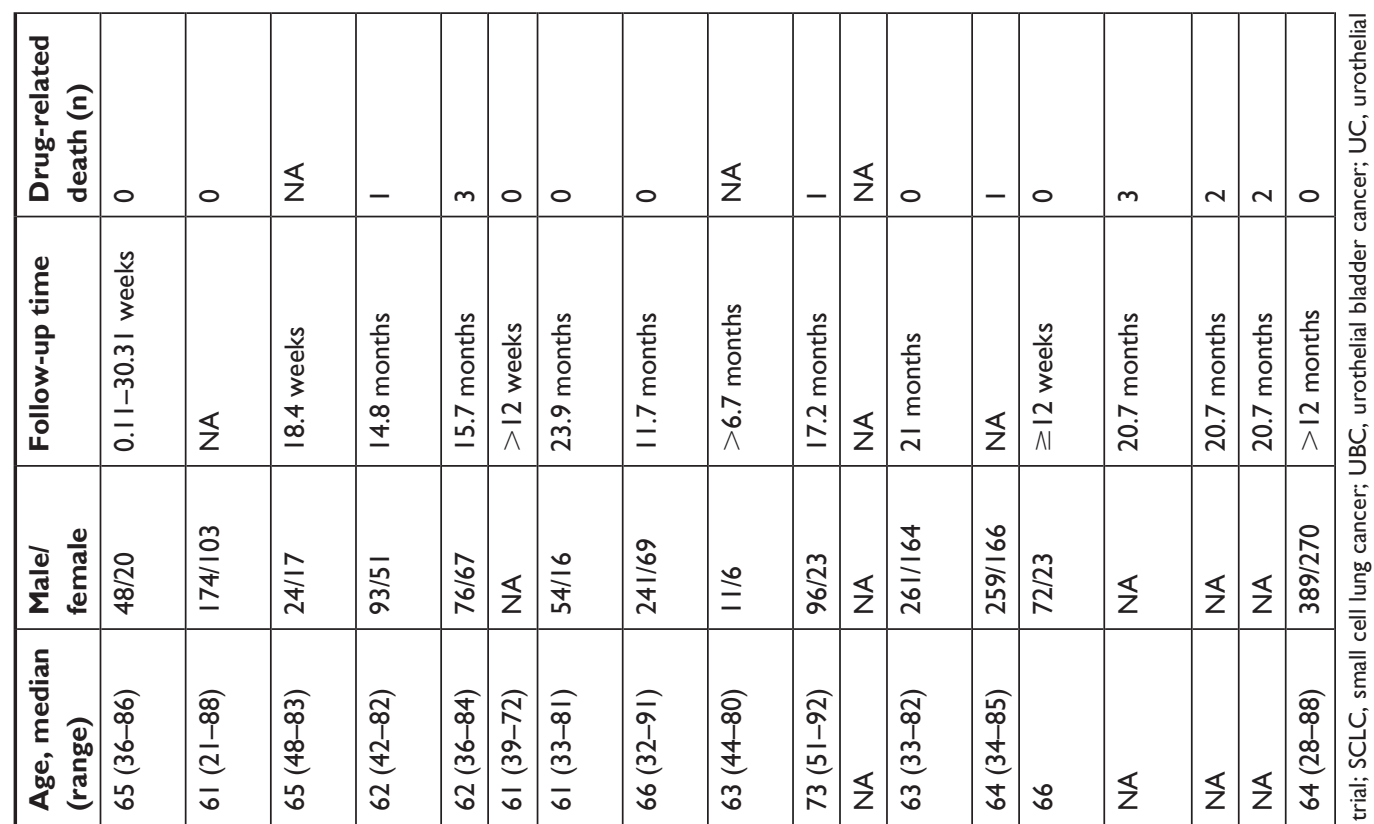

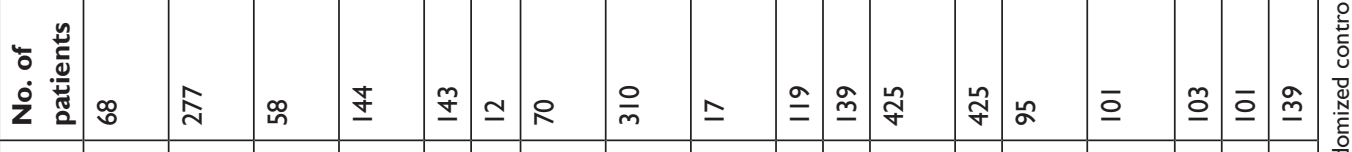

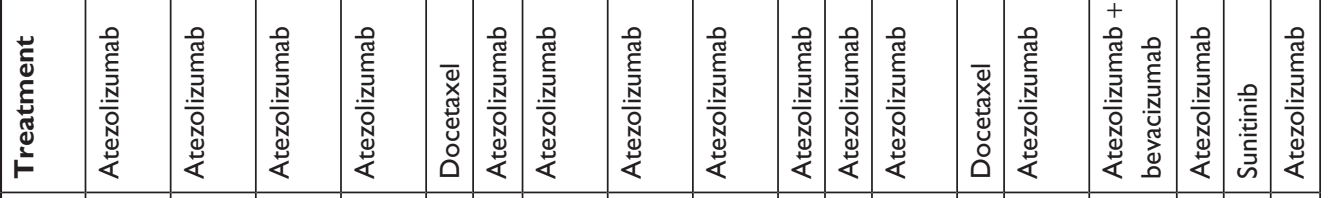

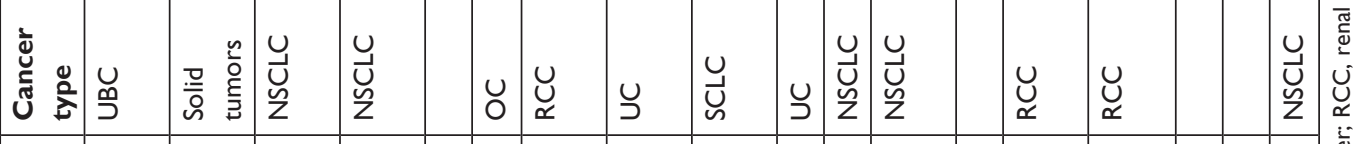

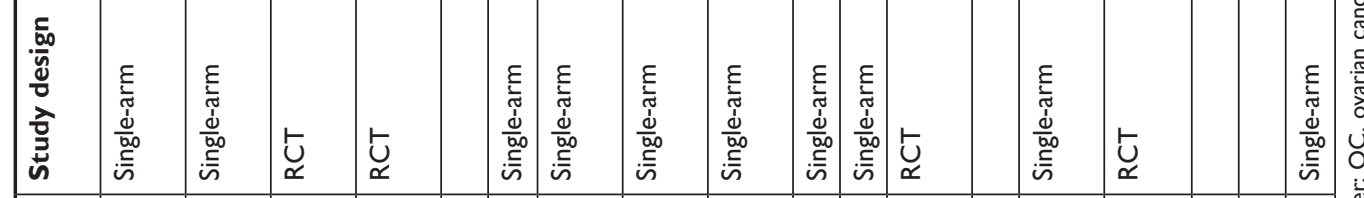

\begin{tabular}{|c|c|c|c|c|c|c|c|c|c|c|c|c|c|}
\hline $\begin{array}{l}\frac{\mathscr{d}}{0} \\
\frac{E}{2} \\
\end{array}$ & - & - & $\simeq$ & $=$ & $\underline{\widetilde{\sigma}}$ & $\underline{\simeq}$ & $=$ & $\underline{.}$ & $==$ & $=\equiv$ & $\underline{\simeq}$ & $=$ & $=$ \\
\hline 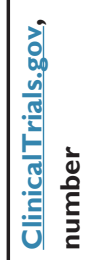 & 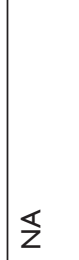 & $\underline{z}$ & $\underline{z}$ & 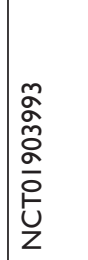 & 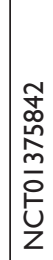 & 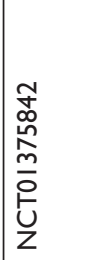 & 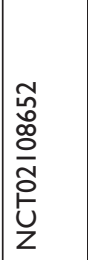 & 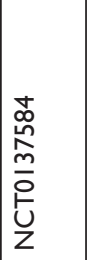 & 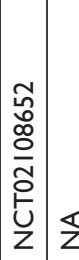 & ẑ & 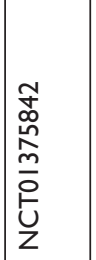 & 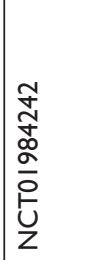 & 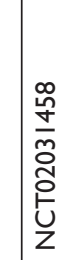 \\
\hline 害 & 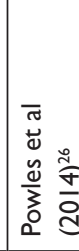 & 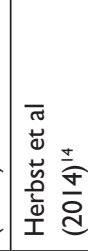 & 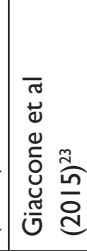 & 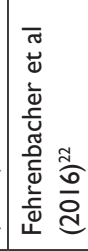 & 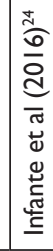 & 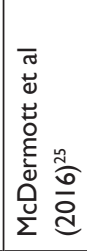 & 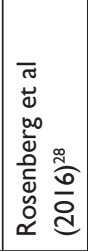 & 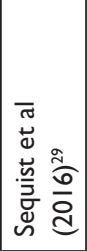 & 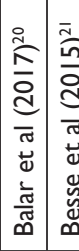 & 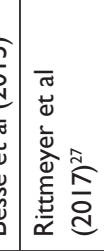 & 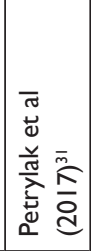 & 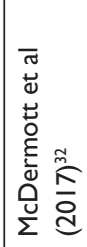 & 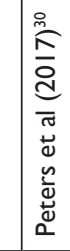 \\
\hline
\end{tabular}


article. Four studies were multicenter randomized controlled trials (RCT), and ten articles were single-arm designed trials. Atezolizumab was administered intravenously at a dose of $15 \mathrm{mg} / \mathrm{kg}$ or $1,200 \mathrm{mg}$ in patients with LC, urothelial bladder cancer, RCC, or OC. Patients in these studies received zero or more prior systematic therapies like surgery, chemotherapy, radiotherapy, and biotherapy. Atezolizumab-related deaths occurred in four patients $(0.17 \%$, unknown causes and respiratory tract infection). Chemotherapy-related deaths occurred in four patients $(0.70 \%$, unknown causes, acute respiratory distress syndrome, and sepsis).

\section{Overall toxicity analysis}

The overall risks of any grade AEs, grade $\geq 3$ AEs, and exhibition of any AEs were used to evaluate the safety of atezolizumab in treating cancers. Among all articles, eleven studies were incorporated in the any grade AE analysis, and 12 articles were included in the grade $\geq 3 \mathrm{AE}$ analysis because some articles had no applicable data. $I^{2}$ and chisquared tests were used to evaluate the variation among studies. We used random effects model because of significant heterogeneity $\left(I^{2}>50 \%, P<0.05\right)$ among studies. The pooled risks of any grade AEs and grade $\geq 3$ AEs were 69\% (95\% CI: $\left.65-73, I^{2}=70.1 \%, P=0.000\right)$ and $13 \%(95 \% \mathrm{CI}: 11-15$, $I^{2}=51.8 \%, P=0.019$ ), respectively (Figure 2). We analyzed the pooled risks of immune-related AEs (irAEs) in this work. The pooled risks of any grade irAEs and grade $\geq 3$ AEs were $13 \%\left(95 \% \mathrm{CI}: 6-21, I^{2}=95.5 \%, P=0.000\right)$ and $3 \%$ (95\% CI: $1-5, I^{2}=74.3 \%, P=0.002$ ), respectively.

In regard to single-arm trials, the overall event rates of atezolizumab-related AEs were assessed and shown in Table 2. Treatment-related AEs happened in multiple organ systems, while most of them had low pooled risks. Obviously, fatigue was the most common $\mathrm{AE}$ that had the highest rate of 0.245 (95\% CI: $0.208-0.285)$. Other common any grade AEs were decreased appetite (13.2\%), nausea (12.3\%), diarrhea $(10.8 \%)$, pyrexia $(10.7 \%)$, pruritus $(9.6 \%)$, cough (9.5\%), edema peripheral (8.6\%), and rash (8.4\%). Besides the general disorders, the most common AEs happened in gastrointestinal system, skin, and respiratory system. In general, the rates of severe events (grade $\geq 3$ ) were quite low. Among the grade $\geq 3$ AEs, the most common ones were fatigue $(2.2 \%)$, anemia $(1.9 \%)$, and dyspnea $(1.9 \%)$. The most common any grade irAEs were rash (4\%), increased aspartate aminotransferase (AST; 1.8\%), increased alanine aminotransferase (ALT; 1.8\%), pneumonitis (1.3\%), colitis $(0.7 \%)$, and hepatitis $(0.3 \%)$. The most common grade $\geq 3$ irAEs was pneumonitis $(0.7 \%)$.
When compared with the AEs between atezolizumab and chemotherapeutics, we found that some AEs like decreased appetite, asthenia, constipation, nausea, and vomiting had no significant difference. Other any grade AEs like alopecia, anemia, fatigue, neutropenia, diarrhea, and peripheral neuropathy occurred less in atezolizumab group than in chemotherapeutics group. We did not analyze the grade $\geq 3$ AEs due to lack of data. The results are shown in Table 3.

\section{Overall efficacy analysis}

The overall ORR, pooled 6-month PFS rate, and 1-year OS rate were used to judge the efficacy of atezolizumab in the cancer treatment. Thirteen articles were included in the ORR analysis, five studies were incorporated in the PFS rate analysis, and seven articles were included in the OS rate analysis. The pooled ORR, 6-month PFS rate, and 1-year OS rate were $21 \%$ (95\% CI: $\left.17-25, I^{2}=81.8 \%, P=0.000\right)$, $36 \%$ (95\% CI: $\left.31-41, I^{2}=76.6 \%, P=0.001\right)$, and 55\% (95\% CI: $49-61, I^{2}=84.3 \%, P=0.000$ ), respectively (Figure 3 ). The median PFS varied from 1.5 to 6.1 months for single-arm trials, whereas the median OS varied from 5.9 to 28.9 months (Table S1). The pooled CRR and PRR were 6\% $(95 \%$ CI: $\left.2-10, I^{2}=82.4 \%, P=0.000\right)$ and $16 \%(95 \% \mathrm{CI}: 10-22$, $\left.I^{2}=82.8 \%, P=0.000\right)$, respectively.

To investigate the source of heterogeneity among studies, we conducted subgroup analysis. When we grouped by type of cancer, the pooled ORR of UC, NSCLC, OC, and RCC were $21 \%$ (95\% CI: 13-30), 24\% (95\% CI: 15-34), 17\% (95\% CI: 0-38), and 22\% (95\% CI: 13-30), respectively. The overall 6-month PFS rates of NSCLC and RCC were 31\% (95\% CI: 28-33) and 41\% (95\% CI: 31-50), respectively. The pooled 1-year OS rates of UC, NSCLC, and RCC were 52\% (95\% CI: 43-61), 53\% (95\% CI: 51-56), and 64\% (95\% CI: 31-97), respectively. When grouped by study phase, the pooled ORR of phase I, II, and III studies were 25\% (95\% CI: 14-35), 19\% (95\% CI: 15-23), and 14\% (95\% CI: 10-17), respectively. The overall 6-month PFS rates of phase I, II, and III studies were $42 \%$ (95\% CI: 35-50), 32\% (95\% CI: 29-35), and 30\% (95\% CI: 26-35), respectively. The pooled 1-year OS rates of phase I, II, and III studies were 64\% (95\% CI: 31-97), 52\% (95\% CI: 49-55), and 55\% (95\% CI: 50-60), respectively. When grouped by study design, the pooled ORR of RCT and single-arm were $28 \%$ (95\% CI: 15-41) and 19\% (95\% CI: 15-23), respectively. The overall 6-month PFS rates of RCT and single-arm were 33\% (95\% CI: 28-39) and 36\% (95\% CI: 25-47), respectively. The pooled 1-year OS rate of RCT and single-arm were 52\% (95\% CI: 45-59) and 57\% (95\% CI: 48-66), respectively. 


\begin{tabular}{|c|c|c|c|}
\hline Study & & ES $(95 \% \mathrm{Cl})$ & Weight (\%) \\
\hline Powles, T. (2014) & $\oiiint 1$ & $0.57(0.46,0.69)$ & 6.44 \\
\hline Herbst, R.S. (2014) & 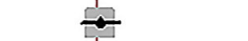 & $0.70(0.65,0.75)$ & 11.92 \\
\hline Fehrenbacher, L. (2016) & $\rightarrow$ & $0.67(0.59,0.75)$ & 9.61 \\
\hline Infante, J.R. (2016) & $\longrightarrow$ & $0.92(0.76,1.07)$ & 4.46 \\
\hline McDermott, D.F. (2016) & 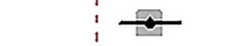 & $0.84(0.76,0.93)$ & 8.90 \\
\hline Rosenberg, J.E. (2016) & $=$ & $0.69(0.64,0.75)$ & 12.18 \\
\hline Sequist, L.V. (2016) & at & $0.65(0.42,0.87)$ & 2.49 \\
\hline Balar, A.V. (2017) & $\approx$ & $0.66(0.58,0.75)$ & 8.93 \\
\hline Rittmeyer, A. (2017) & $\infty$ & $0.64(0.60,0.68)$ & 13.45 \\
\hline Petrylak, D.P. (2018) & $\Rightarrow$ & $0.66(0.56,0.76)$ & 8.01 \\
\hline Peters, S. (2017) & $\approx$ & $0.65(0.61,0.69)$ & 13.60 \\
\hline Overall $\left(I^{2}=70.1 \%, P=0.000\right)$ & $\Leftrightarrow$ & $0.69(0.65,0.73)$ & 100 \\
\hline-1.07 & 1.07 & & \\
\hline
\end{tabular}

B

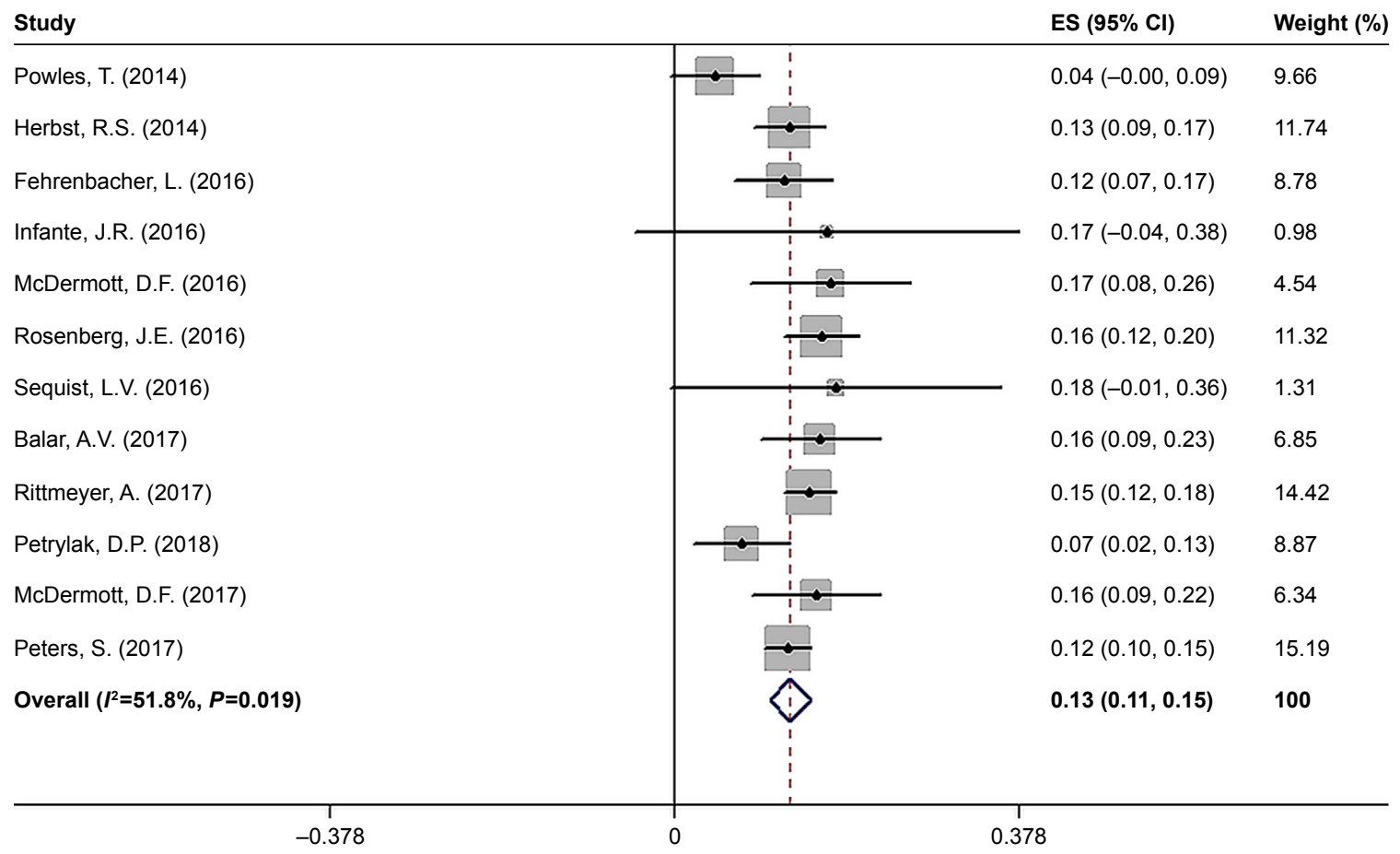

Figure 2 The overall risk of any grade $A E s(\mathbf{A})$ and grade $\geq 3 \mathrm{AEs}(\mathbf{B})$.

Note: Weights are from random effects analysis.

Abbreviations: AEs, adverse events; ES, effect size.

All the results of subgroup analysis in our meta-analysis are shown in Table S2.

ORR data among different PD-L1 expression levels were presented in six studies. PD-L1 positive was defined by a $1 \%$ expression threshold per specimen. As shown in Figure 4A, the OR between PD-L1-positive and PD-L1-negative expression was 2.36 (95\% CI: $\left.1.65-3.38, I^{2}=19 \%, P<0.0001\right)$.

We performed further analyses to evaluate the efficacy between atezolizumab and chemotherapeutics. There were two articles utilizing atezolizumab compared with docetaxel. 
Table 2 Incidence of AEs in any grade or grade $\geq 3$

\begin{tabular}{|c|c|c|c|c|}
\hline \multirow[t]{2}{*}{ AEs } & \multicolumn{2}{|l|}{ Any grade } & \multicolumn{2}{|l|}{ Grade $\geq 3$} \\
\hline & Event rate $(\%, 95 \% \mathrm{Cl})$ & $\begin{array}{l}\text { Statistical } \\
\text { method }\end{array}$ & Event rate $(\%, 95 \% \mathrm{Cl})$ & $\begin{array}{l}\text { Statistical } \\
\text { method }\end{array}$ \\
\hline \multicolumn{5}{|l|}{ General disorders } \\
\hline Fatigue & $24.5(20.8-28.5)$ & Random & $2.2(1.6-3.0)$ & Fixed \\
\hline Pyrexia & $10.7(7.4-15.3)$ & Random & $0.2(0.1-0.6)$ & Fixed \\
\hline Pain & $8.0(2.5-23.0)$ & Random & & \\
\hline Asthenia & $7.3(4.1-12.6)$ & Random & $1.0(0.6-1.6)$ & Fixed \\
\hline Headache & $6.0(3.4-10.4)$ & Random & $0.7(0.2-2.8)$ & Fixed \\
\hline Night sweats & 4.I (2.4-6.8) & Fixed & & \\
\hline Hypotension & $1.9(1.0-3.8)$ & Fixed & $0.7(0.2-2.2)$ & Fixed \\
\hline Alopecia & $0.7(0.3-1.8)$ & Fixed & & \\
\hline \multicolumn{5}{|l|}{ Gastrointestinal disorders } \\
\hline Decreased appetite & | $3.2(9 .|-| 8.6)$ & Random & $0.4(0.2-0.9)$ & Fixed \\
\hline Nausea & | $2.3(9.9-15.2)$ & Random & $0.6(0.3-1.1)$ & Fixed \\
\hline Diarrhea & $10.8(8.6-13.4)$ & Random & $0.6(0.3-1.2)$ & Fixed \\
\hline Constipation & $7.2(2 . I-2 I .6)$ & Random & & \\
\hline Vomiting & $5.9(3.7-9.3)$ & Random & $0.3(0.1-0.9)$ & Fixed \\
\hline Dry mouth & $2.7(1.1-6.2)$ & Fixed & & \\
\hline \multicolumn{5}{|c|}{ Skin and subcutaneous tissue disorders } \\
\hline Pruritus & $9.6(8.2-11.2)$ & Fixed & $0.4(0.1-1.2)$ & Fixed \\
\hline Edema peripheral & $8.6(6.7-11.0)$ & Fixed & & \\
\hline Rash & $8.4(7.1-10.0)$ & Fixed & I.I (0.6-2.1) & Fixed \\
\hline Dry skin & $5.4(3.4-8.4)$ & Fixed & & \\
\hline Dermatitis acneiform & $3.3(1.5-7.1)$ & Fixed & & \\
\hline Stomatitis & $3.3(2.2-4.9)$ & Fixed & & \\
\hline \multicolumn{5}{|c|}{ Respiratory, thoracic, and mediastinal disorders } \\
\hline Cough & $9.5(1.1-50.4)$ & Random & & \\
\hline Chills & $7.0(5.1-9.6)$ & Fixed & & \\
\hline Dyspnea & $6.1(2.3-15.1)$ & Random & $1.9(1.2-2.9)$ & Fixed \\
\hline Influenza-like illness & $5.8(3.3-10.1)$ & Random & $0.7(0.2-2.8)$ & Fixed \\
\hline Pneumonitis & $3.5(2.5-4.8)$ & Fixed & $1.6(0.9-2.7)$ & Fixed \\
\hline \multicolumn{5}{|l|}{ Musculoskeletal disorders } \\
\hline Arthralgia & $7.7(5.5-10.8)$ & Random & $0.5(0.2-1.0)$ & Fixed \\
\hline Myalgia & $5.8(4.5-7.5)$ & Fixed & & \\
\hline Back pain & $4.9(1.5-14.8)$ & Random & & \\
\hline Muscle spasms & $2.7(1 . I-6.2)$ & Fixed & & \\
\hline \multicolumn{5}{|c|}{ Blood and lymphatic system disorders } \\
\hline Anemia & $5.8(3.5-9.5)$ & Random & $1.9(1.3-2.9)$ & Fixed \\
\hline Thrombocytopenia & $2.7(1.1-6.3)$ & Fixed & & \\
\hline Hypophosphatemia & I.8 $(0.9-3.8)$ & Fixed & $\mathrm{I} .5(0.7-3.3)$ & Fixed \\
\hline Neutropenia & $1.5(0.8-2.7)$ & Fixed & & \\
\hline \multicolumn{5}{|c|}{ Metabolism and nutrition disorders } \\
\hline Hypothyroidism & $5.3(4.0-7.1)$ & Fixed & & \\
\hline \multicolumn{5}{|l|}{ Hepatic disorders } \\
\hline AST increased & $3.4(2.5-4.5)$ & Fixed & I.I (0.6-I.8) & Fixed \\
\hline ALT increased & $3.3(2.4-4.6)$ & Fixed & I.I $(0.3-4.1)$ & Random \\
\hline \multicolumn{5}{|l|}{ Nervous system disorders } \\
\hline Peripheral neuropathy & $2.7(1.5-4.9)$ & Random & & \\
\hline
\end{tabular}

Notes: The most common atezolizumab-related any grade AEs were fatigue (24.5\%), decreased appetite (I3.2\%), nausea (I2.3\%), diarrhea (I0.8\%), pyrexia (I0.7\%), pruritus (9.6\%), cough (9.5\%), edema peripheral (8.6\%), and rash (8.4\%). The most common grade $\geq 3$ AEs were fatigue ( $2.2 \%)$, anemia (I.9\%), and dyspnea (I.9\%). $P=0.000$.

Abbreviations: AEs, adverse events; ALT, alanine aminotransferase; AST, aspartate aminotransferase. 
Table 3 Incidence of AEs comparing atezolizumab with chemotherapeutics

\begin{tabular}{|l|l|l|l|}
\hline \multirow{2}{*}{ AEs } & \multicolumn{2}{|l|}{ Any grade } \\
\cline { 2 - 4 } & OR $(95 \% \mathbf{C I})$ & P-value & $\begin{array}{l}\text { Statistical } \\
\text { method }\end{array}$ \\
\hline Alopecia & $0.013(0.005-0.033)$ & 0.000 & Fixed \\
\hline Anemia & $0.406(0.302-0.545)$ & 0.000 & Fixed \\
\hline Decreased appetite & $1.020(0.797-1.307)$ & 0.873 & Fixed \\
\hline Fatigue & $0.629(0.502-0.787)$ & 0.000 & Fixed \\
\hline Neutropenia & $0.087(0.046-0.163)$ & 0.000 & Fixed \\
\hline Asthenia & $0.720(0.345-1.50 I)$ & 0.381 & Random \\
\hline Constipation & $0.765(0.237-2.469)$ & 0.654 & Random \\
\hline Diarrhea & $0.422(0.204-0.869)$ & 0.019 & Random \\
\hline Nausea & $0.546(0.274-1.088)$ & 0.085 & Random \\
\hline Peripheral neuropathy & $0.182(0.036-0.907)$ & 0.038 & Random \\
\hline Vomiting & $0.782(0.312-1.956)$ & 0.599 & Random \\
\hline
\end{tabular}

Abbreviation: AEs, adverse events.

The ORs of ORR, 6-month PFS, and 1-year OS between atezolizumab and chemotherapeutics were 1.06 (95\% CI: 0.76-1.48, $I^{2}=0 \%, P=0.74$ ), 1.26 (95\% CI: 0.97-1.63, $I^{2}=0 \%, P=0.08$ ), and 1.80 (95\% CI: $1.42-2.28, I^{2}=0.0 \%$, $P<0.0001)$, respectively. The result of this analysis is shown in Figure 4B-D. ORR and 6-month PFS showed that the efficacy between atezolizumab and chemotherapeutics had no significant difference. However, 1-year OS suggested that atezolizumab group had significant difference compared with chemotherapeutics. In controlled trials, the total ORs of PFS and OS were 0.95 (95\% CI: $0.83-1.08)$ and 0.73 (95\% CI: $0.73-0.84)$, respectively, indicating that atezolizumab group had a longer OS.

We evaluated the treatment efficiency between atezolizumab and docetaxel in the PD-L1-negative group. PD-L1 negative was defined as the percentage of PD-L1-expressing cells in tumor cells and tumor-infiltrating immune cells $<1 \%$. The ORs of ORR, 6-month PFS, and 1-year OS between atezolizumab and docetaxel were 0.73 (95\% CI: 0.43-1.26, $I^{2}=0 \%, P=0.26$ ), 1.06 (95\% CI: $0.71-1.59, I^{2}=0 \%, P=0.76$ ), and 1.63 (95\% CI: $\left.1.13-2.35, I^{2}=0.0 \%, P=0.008\right)$, respectively. ORR and 6-month PFS showed that the efficacy between atezolizumab and chemotherapeutics had no significant difference. However, 1-year OS suggested that atezolizumab group had significant difference compared with chemotherapeutics. These results were similar to those in all patients regardless of PD-L1 expression.

\section{Assessment of study quality and publication bias}

The methodological quality of each study was assessed by Review Manager 5.2. The risk of bias graph and risk of

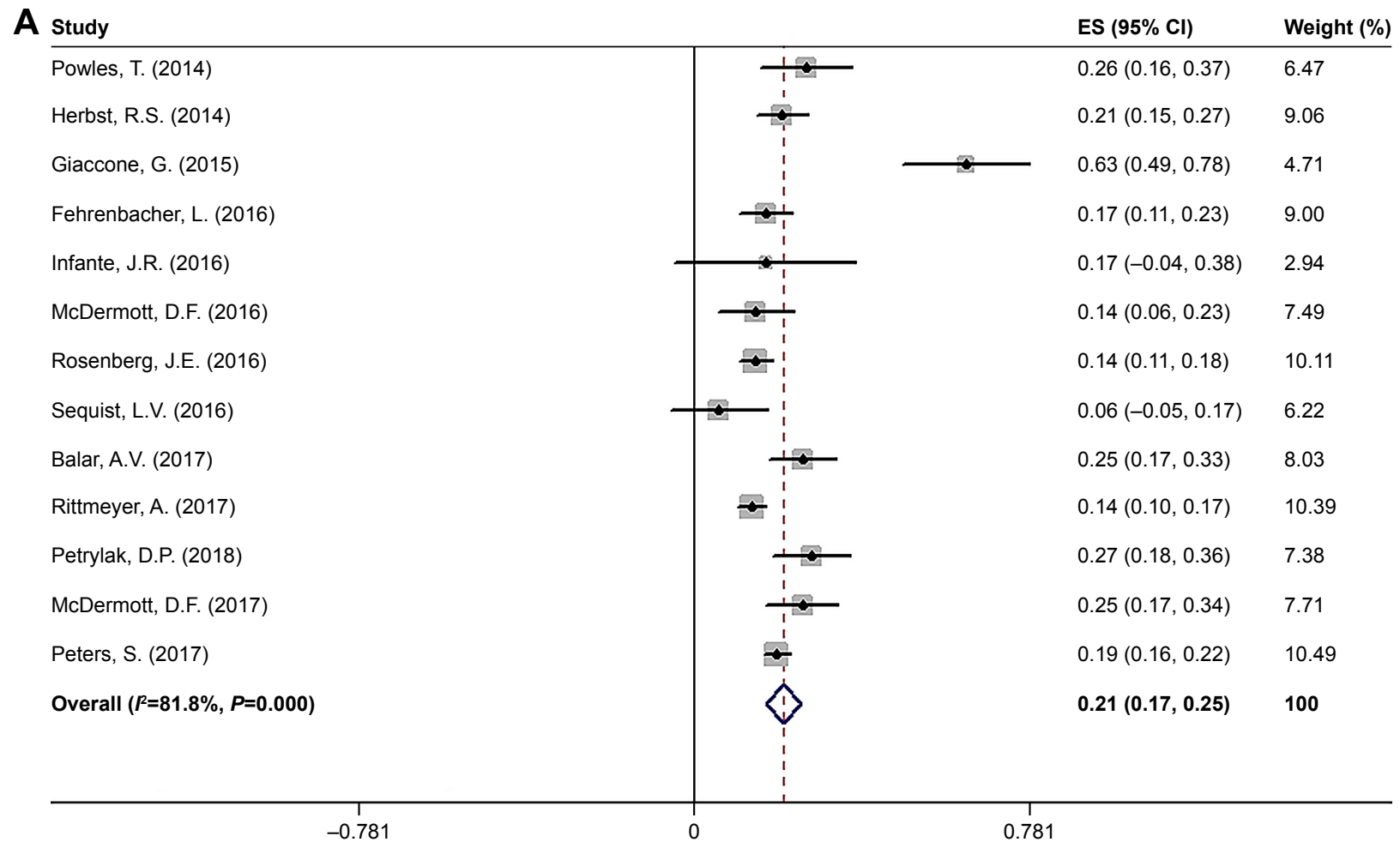

Figure 3 (Continued) 


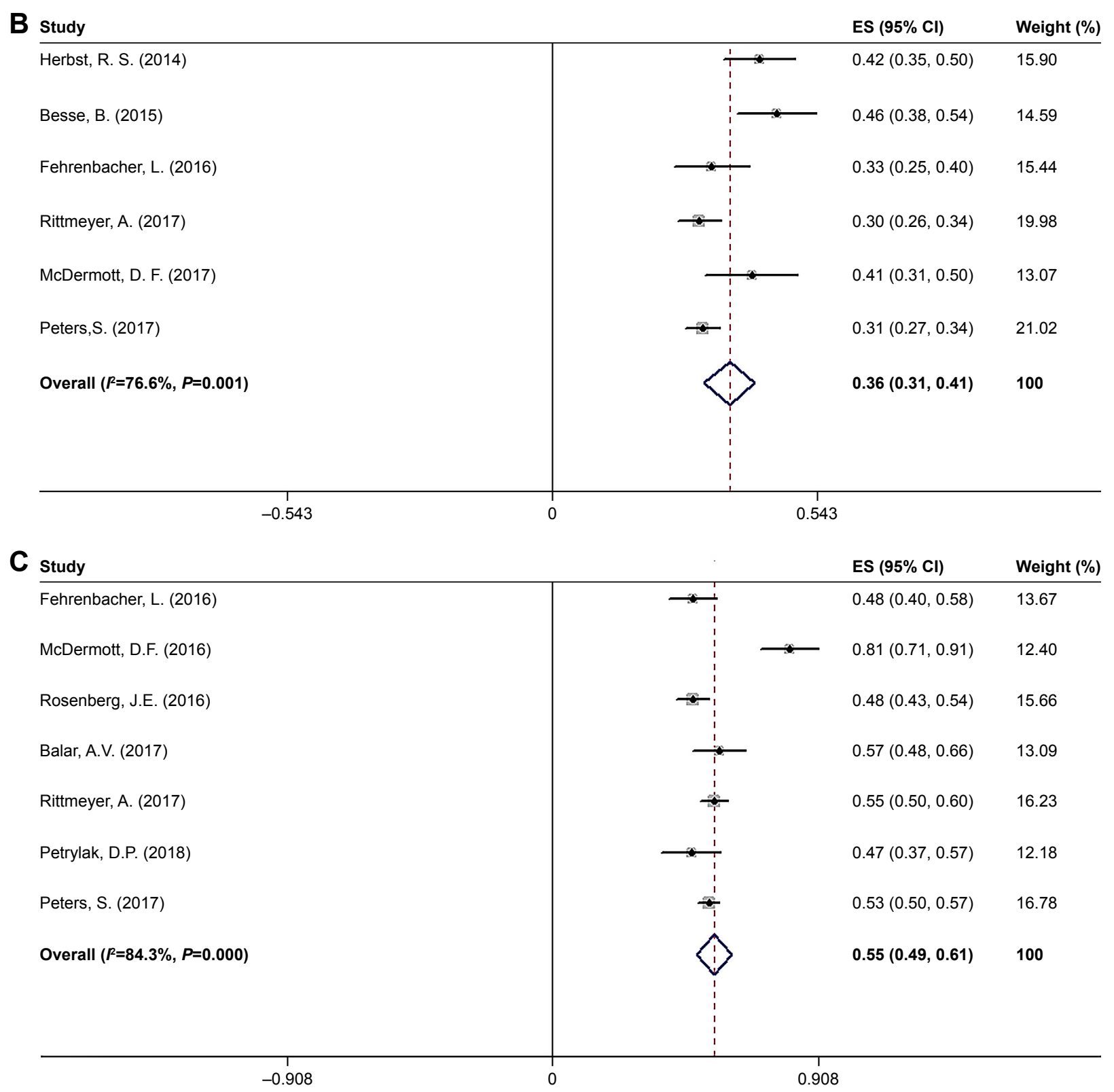

Figure 3 The overall objective response rate (A), 6-month progression-free survival rate (B), and I-year overall survival rate (C) of included studies. Note: Weights are from random effects analysis.

bias summary of all those eligible studies were evaluated (Figure S1). Blinding of participants and personnel was not evaluated as low-risk item because some studies were singlearm trials. The overall risk of bias was evaluated as low risk. Therefore, the quality of the studies was satisfactory.

Begg's and Egger's funnel plot asymmetry tests were used to investigate publication bias in these included studies. There was no significant publication bias in this meta-analysis $(P=0.082)$.

\section{Discussion}

Atezolizumab has been approved by US Food and Drug Administration for the treatment of UC and NSCLC patients. ${ }^{22,27,28}$ According to our review, atezolizumab is usually given as an intravenous infusion of 1,200 $\mathrm{mg}$ over 60 minutes every 3 weeks until progression or unacceptable toxicity. The overall atezolizumab-related death rate was $0.17 \%$, which was much lower than chemotherapeuticsrelated death $(0.70 \%)$. Those atezolizumab-related deaths were associated with respiratory tract infection and unknown causes. We previously reported that nivolumab-related death rate was $0.25 \% .{ }^{12}$ Most of those were associated with pulmonary toxicity, and some were related to ischemic stroke and encephalitis. Chemotherapy-related deaths usually occurred in acute respiratory distress syndrome, sepsis, febrile neutropenia, interstitial lung disease, and pulmonary hemorrhage. 


\begin{tabular}{|c|c|c|c|c|c|c|c|c|c|c|c|}
\hline \multirow{2}{*}{ A } & \multirow{2}{*}{$\begin{array}{l}\begin{array}{l}\text { Study or } \\
\text { subgroup }\end{array} \\
\text { Powles, T. (2014) }\end{array}$} & \multicolumn{2}{|c|}{ PD-L1 positive } & \multicolumn{2}{|c|}{ PD-L1 negative } & \multirow{2}{*}{$\begin{array}{l}\text { Weight } \\
\text { (\%) }\end{array}$} & \multirow{2}{*}{$\begin{array}{l}\begin{array}{l}\text { Odds ratio } \\
\text { M-H, fixed, } 95 \% \text { Cl }\end{array} \\
5.93(1.67,21.04)\end{array}$} & \multirow{2}{*}{$\begin{array}{l}\text { Year } \\
2014\end{array}$} & \multicolumn{3}{|c|}{$\begin{array}{l}\text { Odds ratio } \\
\mathrm{M}-\mathrm{H} \text {, fixed, } 95 \% \mathrm{Cl}\end{array}$} \\
\hline & & 13 & 30 & 4 & 35 & & & & & $\ldots$ & \\
\hline & Herbst, R.S. (2014) & 26 & 90 & 8 & 60 & 15.9 & $2.64(1.10,6.32)$ & 2014 & & 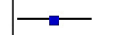 & \\
\hline & Rosenberg, J.E. (2016) & 37 & 207 & 8 & 103 & 20.4 & $2.58(1.16,5.78)$ & 2016 & & $-\cdots$ & \\
\hline & McDermott, D.F. (2016) & 6 & 33 & 2 & 22 & 4.6 & $2.22(0.41,12.18)$ & 2016 & & & \\
\hline & Rittmeyer, A. (2017) & 43 & 241 & 14 & 180 & 30.7 & $2.58(1.36,4.87)$ & 2017 & & -- & \\
\hline & Balar, A.V. (2017) & 20 & 80 & 10 & 39 & 23.5 & $0.97(0.40,2.33)$ & 2017 & & & \\
\hline & Total $(95 \% \mathrm{Cl})$ & & 681 & & 439 & 100 & $2.36(1.65,3.38)$ & & & $\bullet$ & \\
\hline & Total events & 145 & & 46 & & & & & & & \\
\hline & \multicolumn{5}{|c|}{ Heterogeneity: $\chi^{2}=6.18, d f=5(P=0.29) ; I^{2}=19 \%$} & & & 0.01 & 0.1 & 10 & 100 \\
\hline & Test for overall effect: $Z=\angle$ & $.68(P<0.0$ & $0001)$ & & & & & \multicolumn{4}{|c|}{ PD-L1 positive PD-L1 negative } \\
\hline \multirow[t]{7}{*}{$\mathbf{B}$} & $\begin{array}{l}\text { Study or } \\
\text { subgroup }\end{array}$ & \multicolumn{2}{|c|}{$\begin{array}{l}\text { Atezolizumab } \\
\text { Events Total }\end{array}$} & \multicolumn{2}{|c|}{$\begin{array}{l}\text { Chemotherapeutics } \\
\text { Events Total }\end{array}$} & $\begin{array}{l}\text { Weight } \\
(\%)\end{array}$ & $\begin{array}{l}\text { Odds ratio } \\
\mathrm{M}-\mathrm{H} \text {, fixed, } 95 \% \mathrm{Cl}\end{array}$ & Year & \multicolumn{3}{|c|}{$\begin{array}{l}\text { Odds ratio } \\
\text { M-H, fixed, } 95 \% \mathrm{Cl}\end{array}$} \\
\hline & Fehrenbacher, L. (2016) & 24 & 144 & 21 & 143 & 26.3 & $1.16(0.61,2.20)$ & 2016 & & - & \\
\hline & Rittmeyer, A. (2017) & 58 & 425 & 57 & 425 & 73.7 & $1.02(0.69,1.51)$ & 2017 & & & \\
\hline & Total $(95 \% \mathrm{Cl})$ & & 569 & & 568 & 100 & $1.06(0.76,1.48)$ & & & & \\
\hline & Total events & 82 & & 78 & & & & & & & \\
\hline & \multirow{2}{*}{\multicolumn{5}{|c|}{$\begin{array}{l}\text { Heterogeneity: } \chi^{2}=0.12, d f=1(P=0.73) ; I^{2}=0 \% \\
\text { Test for overall effect: } Z=0.33(P=0.74)\end{array}$}} & & & 0.01 & 0.1 & 10 & $0 \quad 100$ \\
\hline & & & & & & & & \multicolumn{4}{|c|}{ Atezolizumab Chemotherapeutics } \\
\hline \multirow[t]{8}{*}{$\mathbf{C}$} & Study or & \multicolumn{2}{|c|}{ Atezolizumab } & \multicolumn{2}{|c|}{ Chemotherapeutics } & Weight & Odds ratio & Year & \multirow{2}{*}{\multicolumn{3}{|c|}{$\begin{array}{l}\text { Odds ratio } \\
\mathrm{M}-\mathrm{H} \text {, fixed, } 95 \% \mathrm{Cl}\end{array}$}} \\
\hline & subgroup & Events & Total & Events & Total & $(\%)$ & $\mathrm{M}-\mathrm{H}$, fixed, $95 \% \mathrm{Cl}$ & & & & \\
\hline & Fehrenbacher, L. (2016) & 47 & 144 & 38 & 143 & 25.0 & $1.34(0.80,2.23)$ & 2016 & & - & \\
\hline & Rittmeyer, A. (2017) & 128 & 425 & 110 & 425 & 75.0 & $1.23(0.91,1.67)$ & 2017 & & & \\
\hline & Total $(95 \% \mathrm{Cl})$ & & 569 & & 568 & 100 & $1.26(0.97,1.63)$ & & & $\gamma$ & \\
\hline & Total events & 175 & & 148 & & & & & & & \\
\hline & \multirow{2}{*}{\multicolumn{5}{|c|}{$\begin{array}{l}\text { Heterogeneity: } \chi^{2}=0.07, d f=1(P=0.79) ; l^{2}=0 \% \\
\text { Test for overall effect: } Z=1.75(P=0.08)\end{array}$}} & & & 0.01 & 0.1 & 10 & 100 \\
\hline & & & & & & & & \multicolumn{4}{|c|}{ Atezolizumab Chemotherapeutics } \\
\hline \multirow[t]{7}{*}{ D } & $\begin{array}{l}\text { Study or } \\
\text { subgroup }\end{array}$ & \multicolumn{2}{|c|}{ Atezolizumab } & \multicolumn{2}{|c|}{$\begin{array}{l}\text { Chemotherapeutics } \\
\text { Events Total }\end{array}$} & $\begin{array}{l}\text { Weight } \\
(\%)\end{array}$ & $\begin{array}{l}\text { Odds ratio } \\
\mathrm{M}-\mathrm{H} \text {, fixed, } 95 \% \mathrm{Cl}\end{array}$ & Year & \multicolumn{3}{|c|}{$\begin{array}{l}\text { Odds ratio } \\
\text { M-H, fixed, } 95 \% \mathrm{Cl}\end{array}$} \\
\hline & Fehrenbacher, L. (2016) & 69 & 144 & 54 & 143 & 27.7 & $1.52(0.95,2.43)$ & 2016 & & $E-$ & \\
\hline & Rittmeyer, A. (2017) & 218 & 425 & 151 & 425 & 72.3 & $1.91(1.45,2.52)$ & 2017 & & & \\
\hline & Total $(95 \% \mathrm{Cl})$ & & 569 & & 568 & 100 & $1.80(1.42,2.28)$ & & & 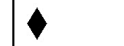 & \\
\hline & Total events & 287 & & 205 & & & & & & & \\
\hline & Heterogeneity: $\chi^{2}=0.69, c$ & $f=1(P=0.4$ & $41) ; l^{2}=0 \%$ & & & & & 0.01 & 0.1 & 110 & 100 \\
\hline & & & 0001) & & & & & & olizu & Chemother & rapeutics \\
\hline
\end{tabular}

Figure 4 The comparison of PD-LI positive with PD-LI negative cancers (A) and atezolizumab with chemotherapeutics (B-D).

Notes: (A) PD-LI-positive cancers had better response to atezolizumab. (B-D) Atezolizumab had better I-year overall survival than chemotherapeutics and had no significant difference with chemotherapeutics in ORR or 6-month progression-free survival.

Abbreviation: PD-LI, programmed death ligand I.

The prevention of treatment-related death with checkpoint inhibitors should start from early detection and aggressive treatment of potentially dangerous irAEs. ${ }^{33}$ In mild cases, clinicians might temporarily discontinue the drug administration. As for severe cases, permanent stoppage should be taken into consideration. Immune modulatory agents including glucocorticoids, infliximab, and azathioprine have been proved helpful in many severe cases.
In our pooled analysis, the total risk of any grade AEs reached $69 \%$, while grade $\geq 3 \mathrm{AEs}$ happened in only $13 \%$ of participants. As we know, immune checkpoint inhibitors can cause activated $\mathrm{T}$ cells to infiltrate normal tissue and enhance nonspecific immune response. This unbalance of immune system results in irAEs, which include general AEs and organ-specific AEs. ${ }^{34}$ As a PD-L1 inhibitor, atezolizumab is more tolerable than PD-1 inhibitors because it allows the 
combination of PD-1 and PD-L2 and leads to less irAEs. ${ }^{14}$ Meanwhile, atezolizumab has a single amino acid substitution in its fragment crystallizable region that normally binds to some immune cells with PD-L1 expression. This design prevents atezolizumab to bind immune cells and avoids antibody-dependent cell-mediated cytotoxicity and resistance to immunotherapy caused by depletion of tumor-specific $\mathrm{T}$ cells with high PD-L1 expression. ${ }^{14,35,36}$

Fatigue is the most common AE in our study and occurred in $24.5 \%$ of patients. Fortunately, almost $2 \%$ of patients experienced severe fatigue. Though the mechanism of fatigue is currently unknown, it is always mild and is much lower than durvalumab and chemotherapies. ${ }^{37}$ Some toxicities may particularly contribute to fatigue including immune-related endocrine disorders (hypothyroidism, hypoadrenalism, and hypopituitarism). Early detection and proper management of these disorders may help to decrease the incidence of fatigue.

Organ-specific irAEs involve skin (pruritus, rash), gut (colitis and diarrhea), endocrine glands (hypothyroidism, hyperthyroidism, and hypophysitis), liver (ALT/AST elevations), lung (pneumonitis), and any other tissues. ${ }^{38,39}$ Gastrointestinal disorders like decreased appetite (13.2\%), nausea $(12.3 \%)$, and diarrhea $(10.8 \%)$ are commonly seen in patients treated with atezolizumab. The incidence rates of severe gastrointestinal disorders are $<1 \%$. The rates of decreased appetite and nausea are not significantly lower than that in patients treated with chemotherapeutics. However, the risk of diarrhea is significantly lower. As reported in our previous study, diarrhea from checkpoint inhibitor therapy arises as a result of colitis. ${ }^{12}$ When patients are present with gastrointestinal disorders, the clinicians should assess for etiology first and then give symptomatic treatment such as antidiarrheal agents. ${ }^{40}$

Different irAEs appeared in different stage of treatment. Skin AEs occurred 3 weeks after the initiation of treatment and was followed by gastrointestinal AEs in about 5 to 10 weeks. Endocrine and liver AEs appear later. ${ }^{41-43}$ Pruritus $(9.6 \%)$, peripheral edema (8.6\%), and rash $(8.4 \%)$ were common skin adverse effects in patients treated with atezolizumab in this analysis. Rash and pruritus might result from anaphylactic reaction or stress response. Lesions come out after the first dose but are worse after each treatment cycle. ${ }^{40}$ Early intervention and routine observation are important to prevent patients from exacerbation. Most rashes associated with immune checkpoint inhibitors can be treated with corticosteroid creams. If pruritus is the prominent system, antipruritic oral drugs, such as hydroxyzine and diphenhydramine, can be administered. ${ }^{44}$ If atypical or severe rash happens, a skin biopsy and oral corticosteroids are recommended. ${ }^{44}$

Pneumotoxicity associated with immune checkpoint inhibitors is common irAEs. Pyrexia, cough, and dyspnea are the most common respiratory symptoms related to atezolizumab in our analysis. Patients with grades 3-4 pneumonitis require hospitalization and intravenous steroid therapy as a general guideline. ${ }^{45}$ If the symptoms could not be improved after 3-5 days of steroids, additional immunosuppressive therapies, such as infliximab, mycophenolate mofetil, or cyclophosphamide, should be considered. ${ }^{41,46}$ The specific immunosuppressive choice, dose, and schedule have not been studied.

Meanwhile, we summarized the ORR, 6-month PFS rate, and 1-year OS rate. Approximately $21 \%$ of participants reached complete response or partial response. Fifty-five percent of patients survived from malignancies for 1 year. Thirty-six percent of patients had stabilization of the disease for half a year. The median PFS varied from 1.5 to 6.1 months for single-arm trials, whereas the median OS ranged from 5.9 to 28.9 months. In RCTs, atezolizumab and chemotherapeutics had no significant difference in ORR and 6-month PFS, whereas 1-year OS rate was higher in atezolizumab group. In brief, all these data demonstrated that atezolizumab had a considerable potential in treating cancers with an acceptable risk profile.

In our work, we demonstrated that PD-L1-positive cancers had better treatment response to atezolizumab than PD-L1-negative cancers. Similar results have been reported in other PD-1/PD-L1 inhibitors. ${ }^{47}$ However, it is still controversial about the definition of $\mathrm{PD}-\mathrm{L} 1$ positive. The standard antibody for PD-L1 detection in immunohistochemistry has not been decided. Otherwise, the heterogeneity of PD-L1 expression between different time points or locations should be noticed. ${ }^{48}$

Heterogeneity might misdirect the interpretation of this meta-analysis, so we conducted subgroup analysis to investigate potential sources. When heterogeneity existed $\left(I^{2}>50 \%\right)$, we used a random effects model; otherwise, we used fixed effects model. Potential sources could come from cancer types, study phase, or study design. Meanwhile, no publication bias was detected in this study; thus, publication bias was not a main source of heterogeneity.

This meta-analysis was conducted to research the safety and efficiency of atezolizumab in the treatment of cancers. Several limitations would be considered. First, patients included in this study were quite heterogeneous with different types of cancers. Further study could verify our results with 
a larger homogeneous patients' pooled analysis. Second, those included studies were not completely double-blinded RCT; the potential performance bias might exit. Finally, some abstracts were incorporated in this work, which might have no complete outcome and then introduced some biases to the final analysis.

\section{Conclusion}

Our meta-analysis demonstrates that atezolizumab has durable outcomes of ORR, 1-year OS rate, and 6-month PFS rate with tolerable AEs in patients with cancers. Major common AEs involved fatigue, decreased appetite, nausea, diarrhea, pyrexia, pruritus, cough, edema peripheral, and rash. The most common severe AEs were fatigue, anemia, and dyspnea. The overall atezolizumab-related death rate was much lower than chemotherapeutics-related death rate. Atezolizumab has better OS and lower risk of AEs compared with chemotherapy.

\section{Acknowledgment}

This study was supported by the National Natural Science Foundation of China (number 81572850).

\section{Author contributions}

YT collected and analyzed the data and wrote the article. HY and RZ performed study selection and quality assessment. HZ edited the pictures. DY and JZ performed manuscript modification. ML provided the idea. All authors contributed toward data analysis, drafting and revising the paper, gave final approval of the version to be published and agree to be accountable for all aspects of the work.

\section{Disclosure}

The authors report no conflicts of interest in this work.

\section{References}

1. Torre LA, Bray F, Siegel RL, Ferlay J, Lortet-Tieulent J, Jemal A. Global Cancer statistics, 2012. CA Cancer J Clin. 2015;65(2):87-108.

2. Devita VT, Chu E. A history of cancer chemotherapy. Cancer Res. 2008;68(21):8643-8653.

3. Sharma P, Allison JP. The future of immune checkpoint therapy. Science. 2015;348(6230):56-61.

4. Zou W, Wolchok JD, Chen L. PD-L1 (B7-H1) and PD-1 pathway blockade for cancer therapy: mechanisms, response biomarkers, and combinations. Sci Transl Med. 2016;8(328):328rv4.

5. Korman AJ, Peggs KS, Allison JP. Checkpoint blockade in cancer immunotherapy. Adv Immunol. 2006;90:297-339.

6. Dong H, Strome SE, Salomao DR, et al. Tumor-associated B7-H1 promotes T-cell apoptosis: a potential mechanism of immune evasion. Nat Med. 2002;8(8):793-800.

7. Iwai Y, Ishida M, Tanaka Y, Okazaki T, Honjo T, Minato N. Involvement of PD-L1 on tumor cells in the escape from host immune system and tumor immunotherapy by PD-L1 blockade. Proc Natl Acad Sci U S A. 2002;99(19):12293-12297.

8. Taube JM, Klein A, Brahmer JR, et al. Association of PD-1, PD-1 ligands, and other features of the tumor immune microenvironment with response to anti-PD-1 therapy. Clin Cancer Res. 2014;20(19): 5064-5074.
9. Garon EB, Rizvi NA, Hui R, et al. Pembrolizumab for the treatment of non-small-cell lung cancer. N Engl J Med. 2015;372(21):2018-2028.

10. Motzer RJ, Escudier B, McDermott DF, et al. Nivolumab versus everolimus in advanced renal-cell carcinoma. NEnglJ Med. 2015;373(19):1803-1813.

11. Robert C, Long GV, Brady B, et al. Nivolumab in previously untreated melanoma without BRAF mutation. NEngl J Med.2015;372(4):320-330.

12. Tie Y, Ma X, Zhu C, et al. Safety and efficacy of nivolumab in the treatment of cancers: a meta-analysis of 27 prospective clinical trials. Int J Cancer. 2017;140(4):948-958.

13. Chen DS, Irving BA, Hodi FS. Molecular pathways: next-generation immunotherapy - inhibiting programmed death-ligand 1 and programmed death-1. Clin Cancer Res. 2012;18(24):6580-6587.

14. Herbst RS, Soria JC, Kowanetz M, et al. Predictive correlates of response to the anti-PD-L1 antibody MPDL3280A in cancer patients. Nature. 2014;515(7528):563-567.

15. Gunturi A, McDermott DF. Nivolumab for the treatment of cancer. Expert Opin Investig Drugs. 2015;24(2):253-260.

16. Eisenhauer EA, Therasse P, Bogaerts J, et al. New response evaluation criteria in solid tumours: revised RECIST guideline (version 1.1). Eur J Cancer. 2009;45(2):228-247.

17. Therasse P, Arbuck SG, Eisenhauer EA, et al. New guidelines to evaluate the response to treatment in solid tumors. European Organization for research and treatment of cancer, National Cancer Institute of the United States, National Cancer Institute of Canada. J Natl Cancer Inst. 2000;92(3):205-216.

18. Higgins JPT, Thompson SG, Deeks JJ, Altman DG. Measuring inconsistency in meta-analyses. BMJ. 2003;327(7414):557-560.

19. Begg CB, Mazumdar M. Operating characteristics of a RANK correlation test for publication bias. Biometrics. 1994;50(4):1088-1101.

20. Balar AV, Galsky MD, Rosenberg JE, et al. Atezolizumab as first-line treatment in cisplatin-ineligible patients with locally advanced and metastatic urothelial carcinoma: a single-arm, multicentre, phase 2 trial. Lancet. 2017;389(10064):67-76.

21. Besse B, Johnson M, Janne PA, et al. 16LBA phase II, single-arm trial (birch) of atezolizumab as first-line or subsequent therapy for locally advanced or metastatic PD-L1-selected non-small cell lung cancer (NSCLC). Eur J Cancer. 2015;51:S717-S718.

22. Fehrenbacher L, Spira A, Ballinger M, et al. Atezolizumab versus docetaxel for patients with previously treated non-small-cell lung cancer (poplar): a multicentre, open-label, phase 2 randomised controlled trial. Lancet. 2016;387(10030):1837-1846.

23. Giaccone G, Camidge DR, Liu SV, et al. 513 safety, activity and biomarkers of atezolizumab (MPDL3280A) with platinum-based chemotherapy (chemo) in non-small cell lung cancer (NSCLC): a phase Ib study. Eur J Cancer. 2015;51:S107-S108.

24. Infante JR, Braiteh F, Emens LA, et al. Safety, clinical activity and biomarkers of atezolizumab (atezo) in advanced ovarian cancer (OC). Ann Oncol. 2016;27(Suppl 6):871P.

25. McDermott DF, Sosman JA, Sznol M, et al. Atezolizumab, an Anti-Programmed Death-Ligand 1 antibody, in metastatic renal cell carcinoma: long-term safety, clinical activity, and immune correlates from a phase Ia study. J Clin Oncol. 2016;34(8):833-842.

26. Powles T, Eder JP, Fine GD, et al. MPDL3280A (anti-PD-L1) treatment leads to clinical activity in metastatic bladder cancer. Nature. 2014; 515(7528):558-562.

27. Rittmeyer A, Barlesi F, Waterkamp D, et al. Atezolizumab versus docetaxel in patients with previously treated non-small-cell lung cancer (OAK): a phase 3, open-label, multicentre randomised controlled trial. Lancet. 2017;389(10066):255-265.

28. Rosenberg JE, Hoffman-Censits J, Powles T, et al. Atezolizumab in patients with locally advanced and metastatic urothelial carcinoma who have progressed following treatment with platinum-based chemotherapy: a single-arm, multicentre, phase 2 trial. Lancet. 2016; 387(10031):1909-1920.

29. Sequist LV, Chiang A, Gilbert J, et al. Clinical activity, safety and predictive biomarkers results from a phase Ia atezolizumab (atezo) trial in extensive-stage small cell lung cancer (ES-SCLC). Ann Oncol. 2016;27(Suppl 6):1425PD. 
30. Peters S, Gettinger S, Johnson ML, et al. Phase II trial of Atezolizumab as first-line or subsequent therapy for patients with programmed DeathLigand 1-Selected advanced non-small-cell lung cancer (birch). J Clin Oncol. 2017;35(24):2781-2789.

31. Petrylak DP, Powles T, Bellmunt J, et al. Atezolizumab (MPDL3280A) monotherapy for patients with metastatic urothelial cancer: long-term outcomes from a phase 1 study. JAMA Oncol. 2018;4(4):537-544.

32. McDermott DF, Atkins MB, Motzer RJ, et al. A phase II study of atezolizumab (atezo) with or without bevacizumab (bev) versus sunitinib (sun) in untreated metastatic renal cell carcinoma (mRCC) patients (pts). J Clin Oncol. 2017;35(Suppl 6):431.

33. Abdel-Rahman O, Helbling D, Schmidt J, et al. Treatment-related death in cancer patients treated with immune checkpoint inhibitors: a systematic review and meta-analysis. Clin Oncol. 2017;29(4):218-230.

34. Devaud C, John LB, Westwood JA, Darcy PK, Kershaw MH. Immune modulation of the tumor microenvironment for enhancing cancer immunotherapy. Oncoimmunology. 2013;2(8):e25961.

35. Deng R, Bumbaca D, Pastuskovas CV, et al. Preclinical pharmacokinetics, pharmacodynamics, tissue distribution, and tumor penetration of antiPD-L1 monoclonal antibody, an immune checkpoint inhibitor. MAbs. 2016;8(3):593-603.

36. Pitt JM, Vétizou M, Daillère R, et al. Resistance mechanisms to immunecheckpoint blockade in cancer: tumor-intrinsic and -extrinsic factors Immunity. 2016;44(6):1255-1269.

37. Nishijima TF, Shachar SS, Nyrop KA, Muss HB. Safety and tolerability of PD-1/PD-L1 inhibitors compared with chemotherapy in patients with advanced cancer: a meta-analysis. Oncologist. 2017;22(4):470-479.

38. Naidoo J, Page DB, Bt L. Toxicities of the anti-PD-1 and anti-PD-L1 immune checkpoint antibodies. Ann oncol. 2015;26(12):2375-2391.

39. Weber JS, Yang JC, Atkins MB, Disis ML. Toxicities of immunotherapy for the practitioner. J Clin Oncol. 2015;33(18):2092-2099.
40. Friedman CF, Proverbs-Singh TA, Postow MA. Treatment of the immune-related adverse effects of immune checkpoint inhibitors: a review. JAMA Oncol. 2016;2(10):1346-1353.

41. Cousin S, Seneschal J, Italiano A. Toxicity profiles of immunotherapy. Pharmacol Ther. 2018;181:91-100.

42. Topalian SL, Sznol M, McDermott DF, et al. Survival, durable tumor remission, and long-term safety in patients with advanced melanoma receiving nivolumab. J Clin Oncol. 2014;32(10):1020-1030.

43. Weber JS, Hodi FS, Wolchok JD, et al. Safety profile of nivolumab monotherapy: a pooled analysis of patients with advanced melanoma. J Clin Oncol. 2017;35(7):785-792.

44. Inno A, Metro G, Bironzo P, et al. Pathogenesis, clinical manifestations and management of immune checkpoint inhibitors toxicity. Tumori. 2017;103(5):405-421

45. Shannon VR. Pneumotoxicity associated with immune checkpoint inhibitor therapies. Curr Opin Pulm Med. 2017;23(4):305-316.

46. Horvat TZ, Adel NG, Dang TO, et al. Immune-related adverse events, need for systemic immunosuppression, and effects on survival and time to treatment failure in patients with melanoma treated with ipilimumab at Memorial Sloan Kettering cancer center. J Clin Oncol. 2015;33(28): 3193-3198.

47. Garassino M, Vansteenkiste J, Kim J-H, et al. PL04a.03: durvalumab in $\geq 3$ rd-line locally advanced or metastatic, EGFR/ALK wild-type NSCLC: results from the phase 2 ATLANTIC study. J Thorac Oncol. 2017;12(1):S10-S11.

48. Madore J, Vilain RE, Menzies AM, et al. PD-L1 expression in melanoma shows marked heterogeneity within and between patients: implications for anti-PD-1/PD-L1 clinical trials. Pigment Cell Melanoma Res. $2015 ; 28(3): 245-253$. 


\section{Supplementary materials}

Table SI PFS and OS of control-arm trials and single-arm trials

\begin{tabular}{|c|c|c|c|c|c|}
\hline \multirow[t]{2}{*}{ PFS } & \multirow[t]{2}{*}{ Study } & \multicolumn{2}{|c|}{ PFS (months, 95\% Cl) } & \multirow[t]{2}{*}{ HR (95\% Cl) } & \multirow[t]{2}{*}{$P$-value } \\
\hline & & Atezolizumab & Chemotherapeutics & & \\
\hline \multirow[t]{2}{*}{ Control-arm trials } & Fehrenbacher et al $(2016)^{22}$ & $2.7(2.0-4.1)$ & $3.0(2.8-4.1)$ & $0.94(0.72-1.23)$ & 0.645 \\
\hline & Rittmeyer et al $(2017)^{27}$ & $2.8(2.6-3.0)$ & $4.0(3.3-4.2)$ & $0.95(0.82-1.10)$ & 0.4928 \\
\hline \multirow[t]{7}{*}{ Single-arm trials } & Infante et al $(2016)^{24}$ & $2.9(1.3-5.5)$ & & & \\
\hline & McDermott et al $(2016)^{25}$ & $5.6(3.9-8.2)$ & & & \\
\hline & Rosenberg et al $(2016)^{28}$ & $2.1(2.1-2.1)$ & & & \\
\hline & Sequist et al $(2016)^{29}$ & $1.5(1.2-2.7)$ & & & \\
\hline & Balar et al $(2017)^{20}$ & $2.7(2.1-4.2)$ & & & \\
\hline & McDermott et al $(2017)^{32}$ & $6.1(5.4-13.6)$ & & & \\
\hline & Peters et al $(2017)^{30}$ & $5.4(3.0-6.9)$ & & & \\
\hline \multirow[t]{2}{*}{ OS } & \multirow[t]{2}{*}{ Study } & \multicolumn{2}{|c|}{ OS (months, $95 \% \mathrm{CI}$ ) } & \multirow[t]{2}{*}{ HR (95\% Cl) } & \multirow[t]{2}{*}{$P$-value } \\
\hline & & Atezolizumab & Chemotherapeutics & & \\
\hline \multirow[t]{2}{*}{ Control-arm trials } & Fehrenbacher et al $(2016)^{22}$ & $12.6(9.7-16.4)$ & $9.7(8.6-12.0)$ & $0.73(0.53-0.99)$ & 0.04 \\
\hline & Rittmeyer et al $(2017)^{27}$ & I3.8(II.8-15.7) & $9.6(8.6-11.2)$ & $0.73(0.62-0.87)$ & 0.0003 \\
\hline \multirow[t]{7}{*}{ Single-arm trials } & Infante et al $(2016)^{24}$ & II.3 (5.5-27.7) & & & \\
\hline & McDermott et al $(2016)^{25}$ & 28.9 (20.0-NE) & & & \\
\hline & Rosenberg et al $(2016)^{28}$ & I I.4 (9.0-NE) & & & \\
\hline & Sequist et al $(2016)^{29}$ & $5.9(4.3-20.1)$ & & & \\
\hline & Balar et al $(2017)^{20}$ & I5.9 (I0.4-NE) & & & \\
\hline & Petrylak et al $(2018)^{31}$ & $10.6(7.5-17.5)$ & & & \\
\hline & Peters et al $(2017)^{30}$ & 20.1 (20.I-NE) & & & \\
\hline
\end{tabular}

Abbreviations: NE, not estimated; OS, overall survival; PFS, progression-free survival.

Table S2 Results of subgroup analysis

\begin{tabular}{|c|c|c|c|c|c|c|c|c|c|c|c|c|}
\hline Subgroup & $\begin{array}{l}\text { Overall } \\
\text { ORR (\%, } \\
95 \% \mathrm{Cl})\end{array}$ & $\begin{array}{l}I^{2} \\
(\%)\end{array}$ & $P$-value & $\begin{array}{l}\text { Statistical } \\
\text { method }\end{array}$ & $\begin{array}{l}\text { Overall } \\
\text { PFS (\%, } \\
95 \% \mathrm{CI})\end{array}$ & $\begin{array}{l}I^{2} \\
(\%)\end{array}$ & $P$-value & $\begin{array}{l}\text { Statistical } \\
\text { method }\end{array}$ & $\begin{array}{l}\text { Overall } \\
\text { OS (\%, } \\
95 \% \mathrm{Cl})\end{array}$ & $\begin{array}{l}I^{2} \\
(\%)\end{array}$ & $P$-value & $\begin{array}{l}\text { Statistical } \\
\text { method }\end{array}$ \\
\hline \multicolumn{13}{|l|}{ Cancer type } \\
\hline UC & $21(13-30)$ & 76.6 & 0.000 & Random & - & - & - & - & $52(43-6 I)$ & 64.6 & 0.000 & Random \\
\hline NSCLC & $24(15-34)$ & 93.2 & 0.000 & Random & $31(28-33)$ & 0.0 & 0.857 & Fixed & $53(5 \mid-56)$ & 10.7 & 0.326 & Fixed \\
\hline OC & $17(0-38)$ & - & - & Fixed & - & - & - & - & - & - & - & - \\
\hline $\mathrm{RCC}$ & $22(15-30)$ & 57.8 & 0.000 & Random & $4 \mid(3 I-50)$ & - & - & Fixed & 64 (3I-97) & 95.5 & 0.000 & Random \\
\hline \multicolumn{13}{|l|}{ Phase } \\
\hline I & $25(14-35)$ & 86.2 & 0.000 & Random & $42(35-50)$ & - & - & Fixed & 64 (3I-97) & 95.5 & 0.000 & Random \\
\hline II & $19(15-23)$ & 59.6 & 0.042 & Random & $32(29-35)$ & 48.0 & 0.146 & Fixed & $52(49-55)$ & 35.1 & 0.202 & Fixed \\
\hline III & $14(10-17)$ & - & - & Fixed & $30(26-35)$ & - & - & Fixed & $55(50-60)$ & - & - & Fixed \\
\hline \multicolumn{13}{|l|}{ Study design } \\
\hline $\mathrm{RCT}$ & $28(|5-4|)$ & 93.5 & 0.000 & Random & 33 (28-39) & 50.6 & 0.132 & Random & $52(45-59)$ & 55.3 & 0.135 & Random \\
\hline $\begin{array}{l}\text { Single- } \\
\text { arm }\end{array}$ & $19(15-23)$ & 58.0 & 0.015 & Random & $36(25-47)$ & 87.2 & 0.005 & Random & $57(48-66)$ & 88.9 & 0.000 & Random \\
\hline
\end{tabular}

Abbreviations: NSCLC, non-small-cell lung cancer; OC, ovarian cancer; ORR, objective response rate; OS, overall survival; PFS, progression-free survival; RCC, renal cell carcinoma; RCT, randomized controlled trial; UC, urothelial carcinoma. 
A

Random sequence generation (selection bias)

Allocation concealment (selection bias)

Blinding of participants and personnel (performance bias)

Blinding of outcome assessment (detection bias)

Incomplete outcome data (attrition bias)

Selective reporting (reporting bias)

Other bias

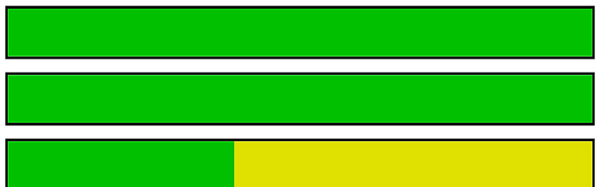

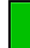

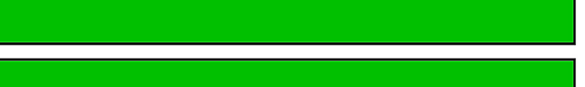

(2)

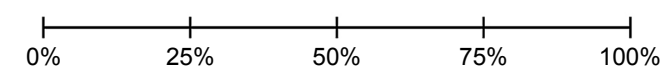

Low risk of bias $\square$ Unclear risk of bias $\square$ High risk of bias

B

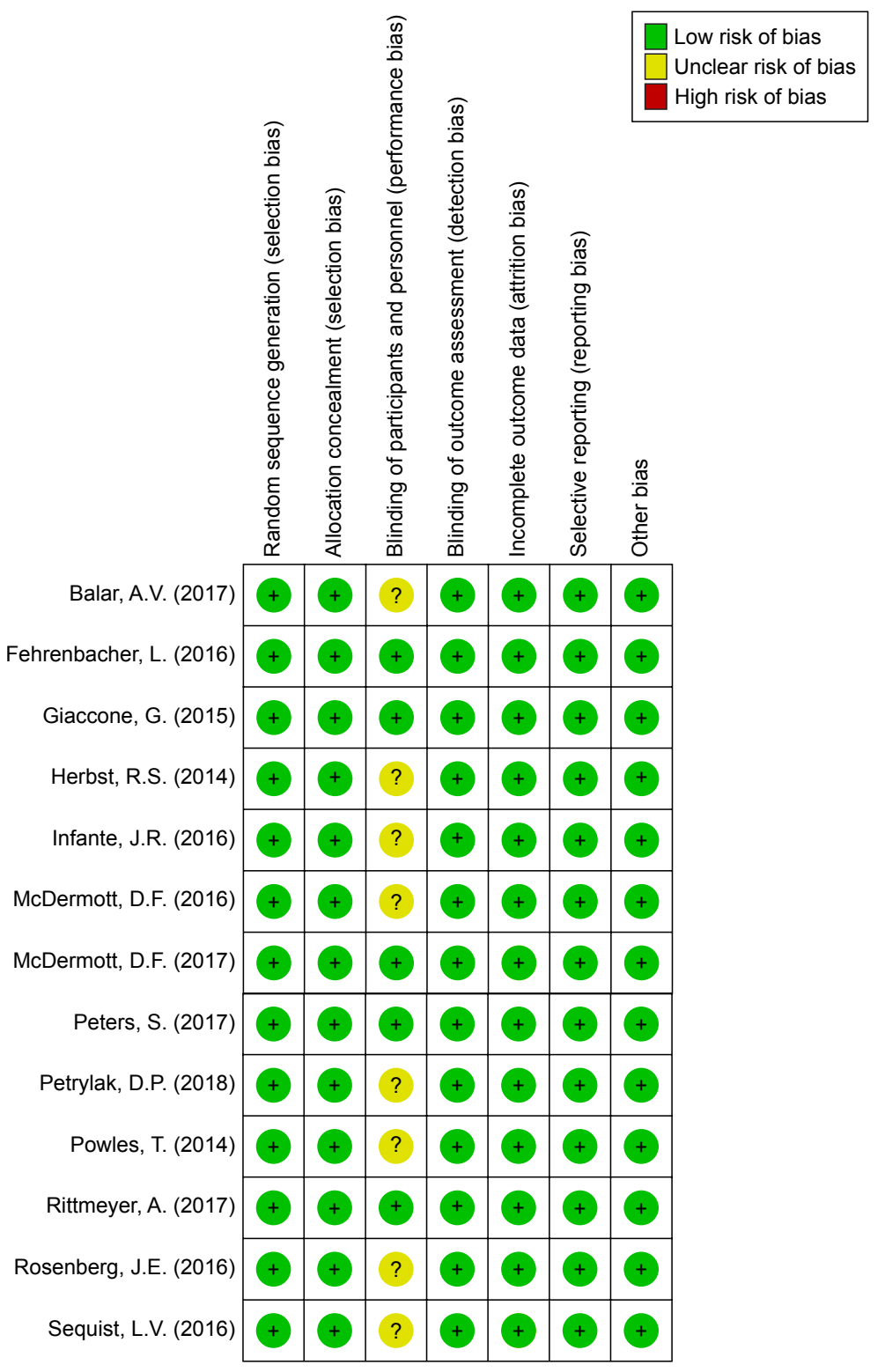

Figure SI The risk of bias graph and the risk of bias summary.

Notes: Blinding of participants and personnel was not evaluated as low-risk item because some studies were dose-escalation and single-arm trials. The overall risk of bias was evaluated as low risk. The risk of bias graph $(\mathbf{A})$ and the risk of bias summary $(\mathbf{B})$. 


\section{Publish your work in this journal}

Drug Design, Development and Therapy is an international, peerreviewed open-access journal that spans the spectrum of drug design and development through to clinical applications. Clinical outcomes, patient safety, and programs for the development and effective, safe, and sustained use of medicines are the features of the journal, which

has also been accepted for indexing on PubMed Central. The manuscript management system is completely online and includes a very quick and fair peer-review system, which is all easy to use. Visit http://www.dovepress.com/testimonials.php to read real quotes from published authors.

Submit your manuscript here: http://www.dovepress.com/drug-design-development-and-therapy-journal 